\title{
FEA ANALYSIS OF THIN STEEL SHEET WITH DIFFERENT LOCATIONS OF REINFORCING RIBS CREATED BY LOCAL LASER TREATMENT
}

\author{
${ }^{1}$ Oleksandr KAPUSTYNSKYI \\ 'Vilnius Gediminas Technical University, Vilnius, Lithuania, EU, oleksandr.kapustynskyi@vilniustech.It
}

https://doi.org/10.37904/metal.2021.4153

\begin{abstract}
The main purpose of the research was to determine the effect of local laser heating on the tensile stress under load. The simulation results show that the different locations and the number of laser tracks (internal reinforcing ribs) on a thin-sheet surface had a great influence on the stress distribution during tensile loads. The finite element analysis of equivalent Von-Mises stresses and stretching of thin-sheet steals acknowledge that the samples with the internal reinforcing ribs have a greater resistance to tensile load.
\end{abstract}

Keywords: Thin steel sheet, reinforcing ribs, laser treatment, FEA modelling

\section{INTRODUCTION}

In most ways, existing methods to increase the stiffness and strength of thin-sheet metal plates are present in the relationship between construction geometry and their stiffness. To increase stiffness can be created additional ribs or thick areas, but at the same time, it will increase the size and weight of the thin-sheet metal plate [1].

Every year, the development of new technologies for processing metal materials allows better control and to improve of the metals properties. Local laser heating is a new modern technique that allows a change and creation of certain zones within the material, the general properties of which will differ significantly from the basic metal structure [2]. Local laser heat treatment is a heating process with or without the melting of the base material. Due to laser treatment, the microstructure and properties of the materials can be controlled changed; for example, it's possible to increase their stiffness or hardness. To influence the stiffness of the metal structure and significantly increase its tensile strength it is enough to know the distribution and values of internal stresses that arise in the structure during loading. Thus, using local laser heating, we will be able to create special zones with internal stiffeners, which will significantly increase the mechanical properties of the structure while maintaining the original weight and dimensions [3].

Finite element analysis (FEA) is an effective, common, forceful numerical method and design tool for the nonlinear analysis of different structures.

The article discusses the use efficiency of local laser heating for creating reinforcing ribs in thin sheet steel. A finite element analysis of the effect of different locations and distances between laser paths on the stress distribution under tensile loads has been carried out.

\section{AIM OF THE STUDY}

The main goal of this study was to evaluate the effect of laser treatment on tensile loads as well as to determine a sufficient number of laser tracks to increase the tensile strength of the material.

The FEA modelling and nonlinear mechanical analysis of tensile stress distribution of thin steel sheets treated by laser for their strengthening are presented in this work. 
Another goal of this research was to assess how the different locations and sizes of laser tracks influence the tensile stress of sheet material.

The experiment used the Ansys Workbench 2020 R1 software for modelling steel sheet tensile tests under workloads.

\section{OBJECT OF THE STUDY}

According to the International Organization of Motor Vehicle Manufacturers, 77.6 million vehicles were produced in 2020. [4] On average, $900 \mathrm{~kg}$ of steel is used per vehicle. Depending on the total mass of the vehicle, the steel in the vehicle is distributed in different ways, but we are interested in the part that is used in the body structure, panels, doors and trunk closure to ensure high strength and energy absorption in the event of an accident - which is approximately $40 \%$ of the total weight car. New grades of Advanced High-Strength Steels (for example S550MC) enable carmakers to reduce vehicle component weight by $25-39 \%$ and total vehicle weight by $8-10 \%$ compared to conventional steel. When applied to a typical five-passenger family car, the overall weight of the vehicle is reduced by $100-150 \mathrm{~kg}$, which corresponds to a lifetime saving of 2-3 tonnes of greenhouse gases over the vehicle's total life cycle. This saving in emissions can be more than the total amount of $\mathrm{CO} 2$ emitted during the production of all the steel in the vehicle. [5] The use of local laser processing of thin sheet steels can help to further reduce the overall entire weight of the structure while maintaining high strength characteristics of the material.

Structural hot rolled carbon steel $(1.0986, \mathrm{~S} 550 \mathrm{MC})$ containing less than $0.3 \%$ carbon was used in this work (Table 1).Chemical composition of steel 1.0986 (wt\%): 0.12C; 0.5Si; 1.8Mn; 0.015S; $0.025 \mathrm{P} ; 0.2 \mathrm{~V} ; 0.09 \mathrm{Nb}$; $0.15 \mathrm{Ti} ; 0.015 \mathrm{Al}$.

Table 1 Mechanical properties of steel 1.0986 [6]

\begin{tabular}{|c|c|c|c|c|}
\hline $\begin{array}{c}\text { Elastic modulus } \\
\text { E, (GPa) }\end{array}$ & $\begin{array}{c}\text { Yield strength } \\
\mathbf{R}_{\mathbf{0 . 2}} \text {, (Mpa) }\end{array}$ & $\begin{array}{c}\text { Tensile strength } \\
\mathbf{R m}, \mathbf{( M p a )}\end{array}$ & $\begin{array}{c}\text { Relative extension } \\
(\%)\end{array}$ & $\begin{array}{c}\text { Hardness } \\
\text { (HBW) }\end{array}$ \\
\hline $190-220$ & 550 & 600 & Min 12 & 341 \\
\hline
\end{tabular}

\section{METHODOLOGY OF RESEARCH}

An Ansys Workbench software was used for FEA simulation of the tensile stress of laser-treated thin sheet metal plate. Appropriate mesh models of laser-treated thin sheet metal plates was done with element quality more than 0.13 for each specimens without highly distorted elements.

The dimensions of the thin sheet metal $(100 \times 5 \times 2 \mathrm{~mm}$ and $100 \times 20 \times 2)$, area of laser-treatment $(20 \times 5$ $\mathrm{mm})$, depth of treatment $(0.35 \mathrm{~mm})$ are identical in all the FEA models created (Figure 1).
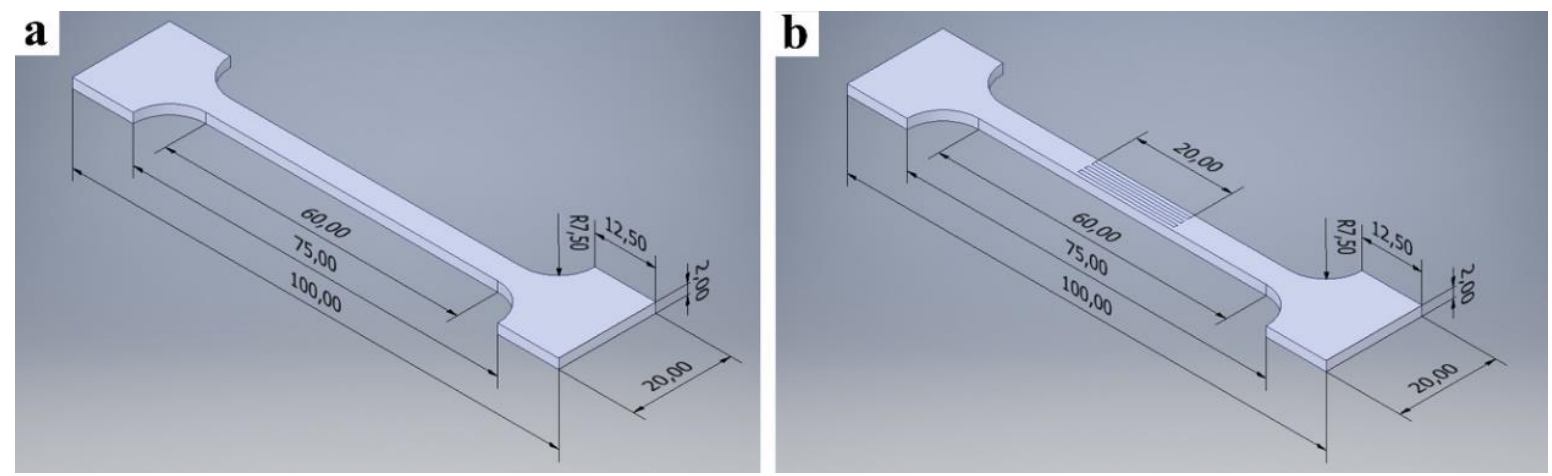

Figure 1 General view of 3D model: $a$ - untreated plate; $b$ - location of laser-treated area 
Three options are presented for the location of the laser-treated area on a sheet sample (strips horizontally, vertically and at an angle of 45 degrees). Three options are also used for the distances between the lasertreated tracks (with overlap, distances of $0.35 \mathrm{~mm}$ and $0.7 \mathrm{~mm}$ ) (Figure 2, Table 2).

Table 2 Variants of FEA model geometry

\begin{tabular}{|c|c|c|c|}
\hline $\begin{array}{c}\text { Location of laser-treated } \\
\text { area }\end{array}$ & $\begin{array}{c}\text { Distances between the } \\
\text { laser-treated tracks } \\
\text { (mm) }\end{array}$ & $\begin{array}{c}\text { Number of laser tracks in } \\
\text { treated area } \\
\text { (pcs) }\end{array}$ & Abbreviation of case \\
\hline \multirow{3}{*}{$\begin{array}{c}\text { Reinforced strips } \\
\text { horizontally }\end{array}$} & 0.7 & 6 & I-I \\
\cline { 2 - 4 } & 0.35 & 8 & I-II \\
\hline \multirow{4}{*}{ Reinforced strips vertically } & Overlap & 12 & I-III \\
\cline { 2 - 4 } & 0.7 & 28 & II-I \\
\hline \multirow{3}{*}{$\begin{array}{c}\text { Reinforced strip at an } \\
\text { angle of 45 degrees }\end{array}$} & 0.35 & 36 & II-II \\
\cline { 2 - 4 } & Overlap & 54 & II-III \\
\cline { 2 - 4 } & 0.7 & 24 & III-I \\
\hline Untreated plate & 0.35 & 32 & III-II \\
\hline & Overlap & 54 & III-III \\
\hline
\end{tabular}

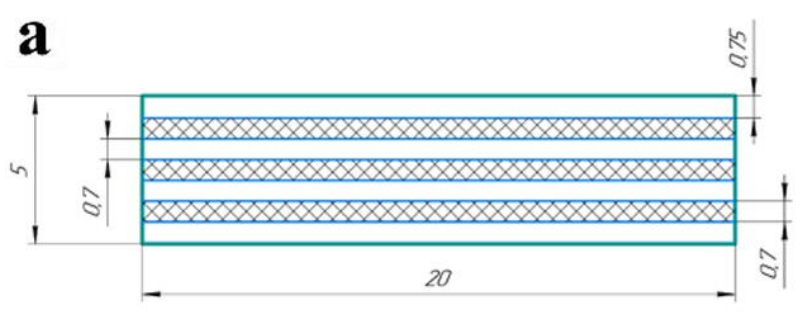

b

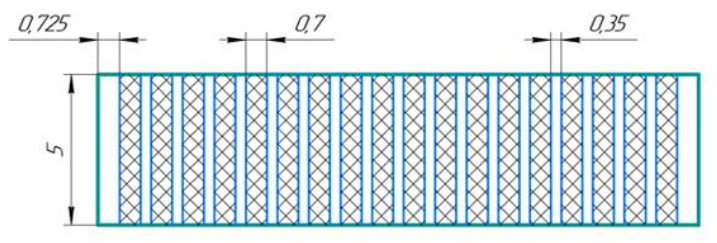

c

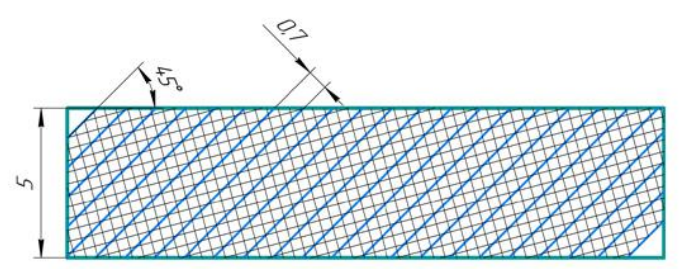

d

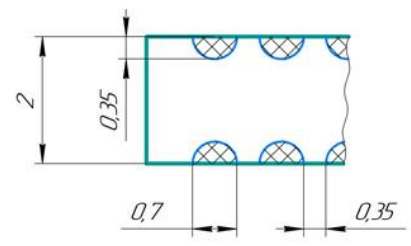

Figure 2 General view of laser treated area: a - case I-I; b - case II-II; c - case III-III; d - cross-section view of laser track case III-II

Two different material properties (for base material and laser-treated tracks) were used for the FEA model (Table 3). Tensile test was done according to ISO 6892-1:2019 [7]. Boundary conditions of the modelling scenarios: one side of the plate, fixed, 0 degree of freedom; second side of the plate - displacement, 1 degree of freedom. The maximum applied force was $3750 \mathrm{~N}$ (Figures 3, 4).

Table 3 Mechanical properties of base metal and laser treated layer used to FEA simulation $[9,10,11]$

\begin{tabular}{|c|c|c|c|c|}
\hline Material & $\begin{array}{c}\text { Modulus of Elasticity } \\
\mathbf{E}(\mathbf{G P a})\end{array}$ & $\begin{array}{c}\text { Shear Modulus } \\
\mathbf{G}(\mathbf{G P a})\end{array}$ & $\begin{array}{c}\text { Yield strength } \\
\boldsymbol{\sigma}_{0.2}(\mathbf{M P a})\end{array}$ & $\begin{array}{c}\text { Ultimate Strength } \\
\boldsymbol{\sigma}_{\mathbf{B}}(\mathbf{M P a})\end{array}$ \\
\hline Base metal & 212 & 82.1 & 550 & 600 \\
\hline Laser treated layer & 262 & 101.7 & 660 & 720 \\
\hline
\end{tabular}


Tetrahedral elements were used to mesh the model of the metal thin sheet plate. The mesh size was from 0.55 to $0.95 \mathrm{~mm}$. The numerical investigation of the physically nonlinear problem was solved for the bending case. A relatively simple plasticity model (Bilinear Isotropic Hardening model) was used $[8,12]$.

The stress-strain curves of the basic metal and the treated layer are provided from experimental data, but the dependences of the nonlinear part of the curves are simplified to linear, as is customary with the Bilinear Isotropic Hardening model. [8].
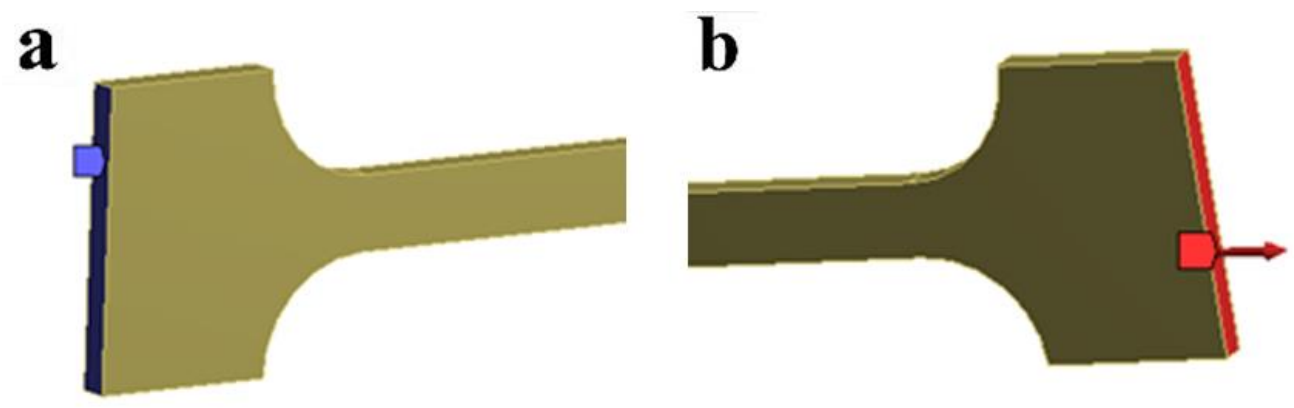

Figure 3 a - fixed support; $b$ - applied force loads

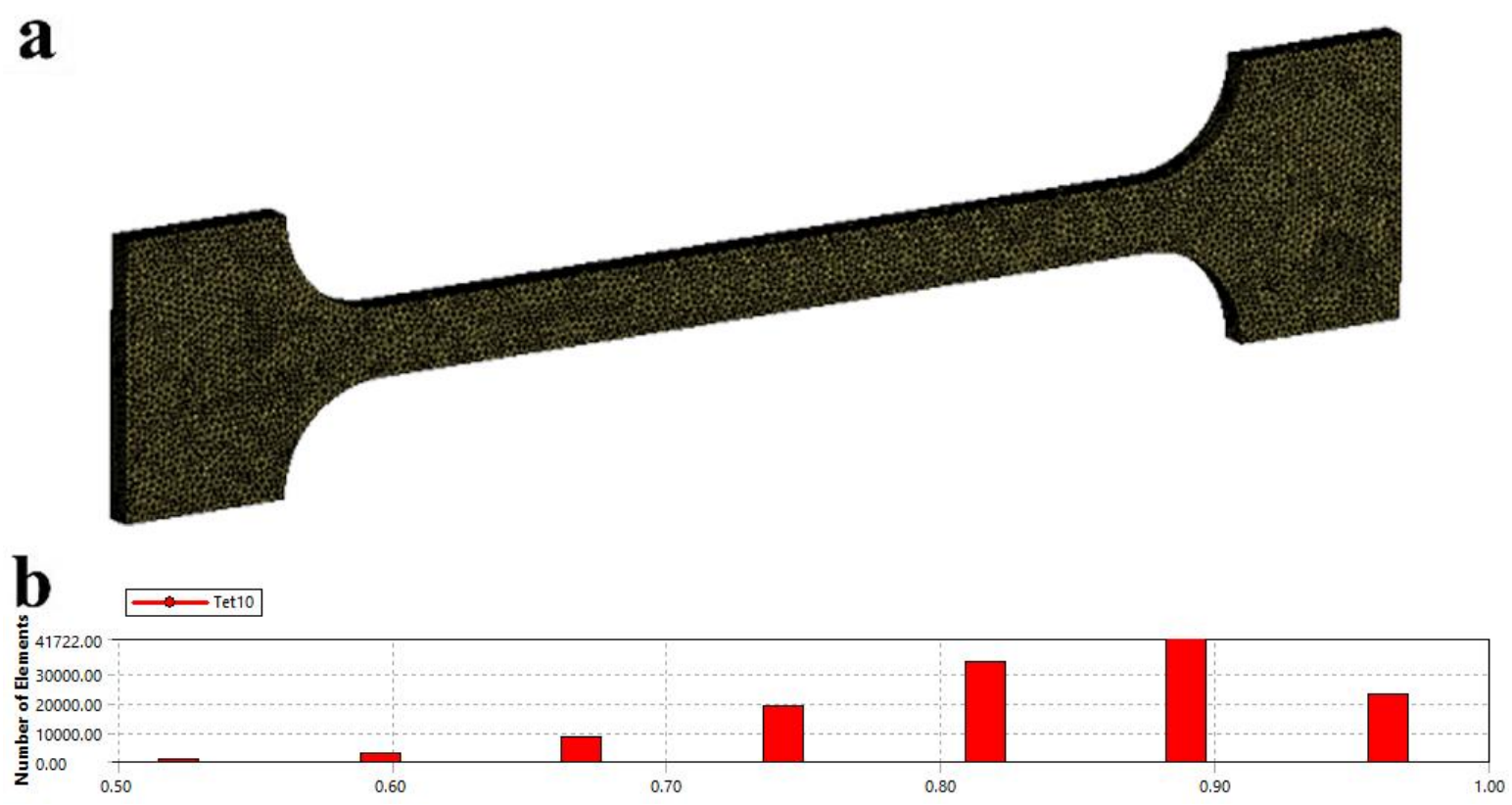

Figure 4 a - 3D meshing model; $b$ - number of meshing elements

\section{RESULTS}

The results of the FEA simulationand their analysis (Figures 5-8, Table 4) shows that the greatest strengthening effect was achieved when the sheet steel was laser treated with overlapping laser tracks under 45 degrees. The difference of achieved maximal Von Mises equivalent stresses in the treated samples to comparison with an untreated thin sheet plate was from $30 \%$ up to $38 \%$. Differences in the efficiency of the application of laser treatment with overlapping and discontinuous surface treatment (with different distances between laser tracks) were only $2-3.5 \%$. Thus, it is more reasonable to use laser processing with a distance between the tracks of about $0.35-0.7 \mathrm{~mm}$, since it requires significantly less energy consumption, which makes the method more economical. 
Table 4 Results of FEA simulation of the elastoplastic deformation

\begin{tabular}{|c|c|c|}
\hline Sample & Max.Deformation (mm) & Von Mises equivalent stress (MPa) \\
\hline Untreated sample (X) & 5.7807 & 510.88 \\
\hline Treated sample I-I & 5.5065 & 550.21 \\
\hline Treated sample I-II & 5.4128 & 553.74 \\
\hline Treated sample I-III & 5.2318 & 535.2 \\
\hline Treated sample II-I & 5.4727 & 537.69 \\
\hline Treated sample II-II & 5.3732 & 548.84 \\
\hline Treated sample II-III & 5.1663 & 546.64 \\
\hline Treated sample III-I & 5.2725 & 551.76 \\
\hline Treated sample III-II & 5.2493 & 565.76 \\
\hline Treated sample III-III & 5.1337 & \\
\hline
\end{tabular}

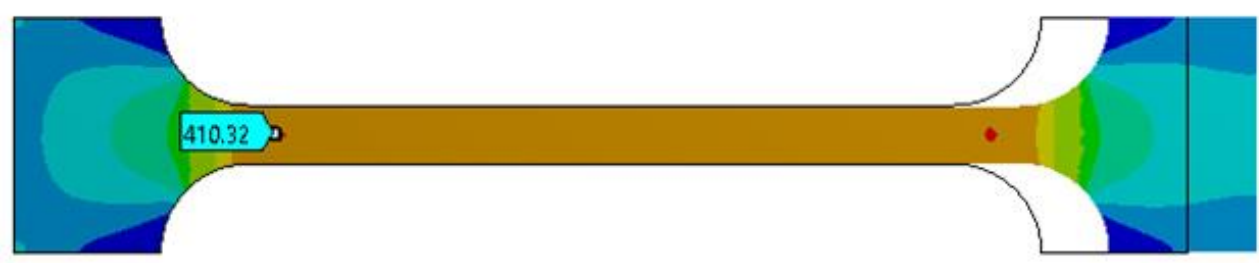

\begin{tabular}{|l}
410.88 Max \\
410 \\
358.77 \\
307.54 \\
256.31 \\
205.08 \\
153.85 \\
102.61 \\
51.384 \\
$\mathbf{0 . 1 5 2 8 7}$ Min
\end{tabular}

Figure 5 Test sample X: Max. Deformation $5.7807 \mathrm{~mm}$; Von Mises equivalent stress $410.88 \mathrm{MPa}$

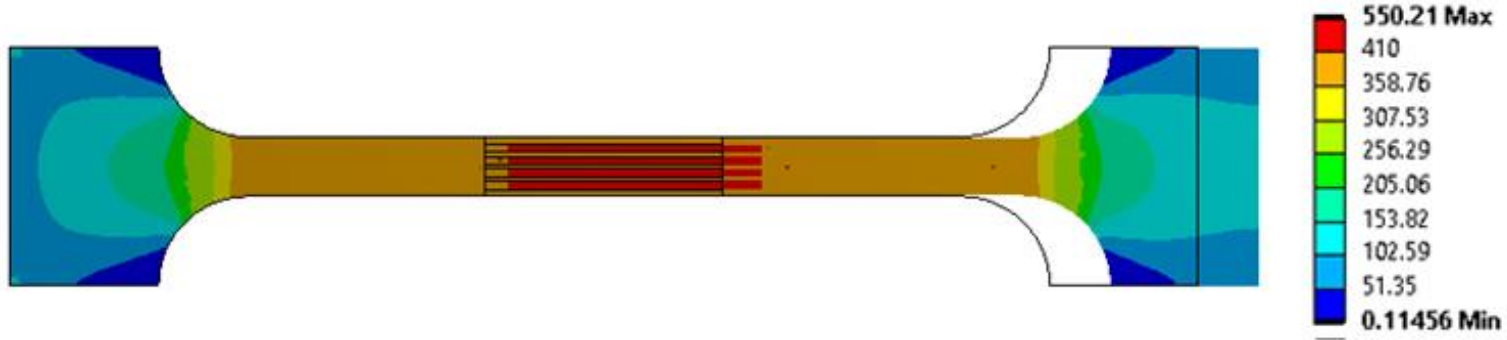

Figure 6 Test sample I-II: Max. Deformation $5.4128 \mathrm{~mm}$; Von Mises equivalent stress $550.21 \mathrm{MPa}$

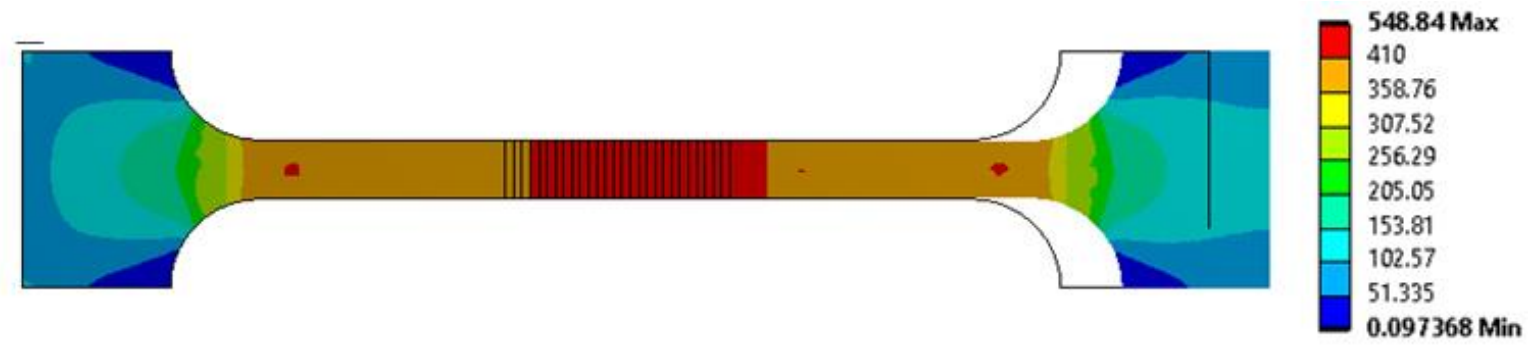

Figure 7 Test sample II-III: Max. Deformation $5.1663 \mathrm{~mm}$; Von Mises equivalent stress $548.84 \mathrm{MPa}$ 


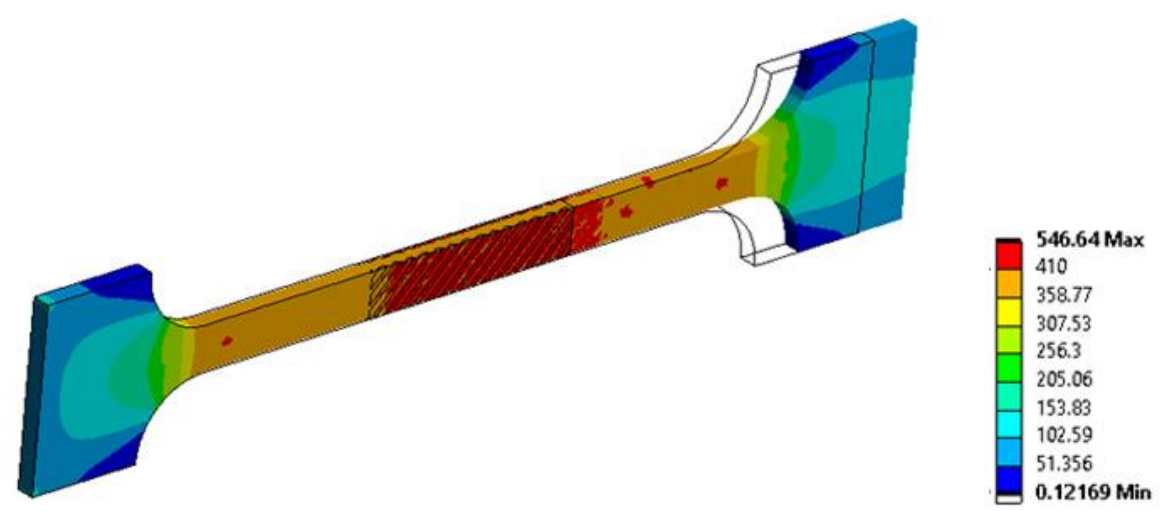

Figure 8 Test sample III-I: Max. Deformation 5.2725 mm; Von Mises equivalent stress $546.64 \mathrm{MPa}$

\section{CONCLUSIONS}

The results of FEA simulations of the tensile test established that local laser processing can be used to resist tensile loads thin sheet steel S550MC by up to $38 \%$, as an alternative to the application of complex geometric shapes or additional strengthening elements.

The FEA method can be used for the prediction of the required laser treatment area - geometry and localization of processed area, depth of laser penetration, orientation, and quantity of laser tracks.

\section{REFERENCES}

[1] JÄRVENPÄÄ, A., JASKARI, M., HIETALA, M., MÄNTYJÄRVI, K. Local Laser Heat Treatments of Steel Sheets. Physics Procedia. 2015, vol. 78, pp. 296-304.

[2] ELAGINA, O. Technological Methods To Improve The Wear Resistance Of Machine Part. Russia: Logos, 2009.

[3] KAPUSTYNSKYI, O., VIŠNIAKOV, N., ČERNAŠĖJUS, O., GOLOVKO, L., CHAYEUSKI, V. Optimization of the Parameters of Local Laser Treatment for the Creation of Reinforcing Ribs in Thin Metal Sheets. In: Proceedings of 24th International Conference "MECHANIKA 2019". 2019, pp. 71-75.

[4] Oica.net. 2020 Statistics [online]. [viewed 2021-06-28] Available from: https://www.oica.net/category/productionstatistics/2020-statistics/

[5] Worldsteel.org. Steel In Automotive [online]. [viewed 2021-06-28] Available from: https://www.worldsteel.org/steelby-topic/steel-markets/automotive.html

[6] European Committee for Standardization. EN 10149-2:1996: Specification for hot-rolled flat products made of high yield strength steels for cold forming. CEN: Brussels, Belgium, 1996.

[7] International Organization for Standardization. ISO 6892-1:2019: Metallic materials-Tensile Testing. International Organization for Standardization: Geneva, Switzerland, 2019.

[8] Fea-cae-engineering.com. Element Types [online]. [viewed 2021-06-28] Available from: $\underline{\text { http://fea-cae- }}$ engineering.com/FEA-CAE-Engineering/element types.htm.

[9] ZHUKOV, A.A., LUZHNIKOV, A.P., DYINKINA, S.Ya. Engineering materials. Mashinostroenie: Moscow, Russia, 1967; pp. 8-15.

[10] DVORKIN, L.I. Building materials science. Russian-English Reference Book. Infra-Inzheneriya: Moscow-Vologda, Russia, 2017; pp. 249-294. ISBN 978-5-9729-0176-0.

[11] TSIKLIS, D.S. Technique of physical and technical research at high and ultrahigh pressures. Himiya: Moscow, Russia. 1965; pp. 15-17.

[12] JONES, R. Deformation Theory Of Plasticity. Blacksburg, Va.: Bull Ridge Pub, 2009.

[13] KAPUSTYNSKYI, O., VIŠNIAKOV, N. Laser Treatment for Strengthening of Thin Sheet Steel. Advances in Materials Science and Engineering, Hindawi. [online]. 2020, pp.1-13. Available from: https://doi.org/10.1155/2020/5963012. 